\title{
Karakteristik preeklampsia di RSUP Prof. Dr. R. D. Kandou Manado
}

\author{
${ }^{1}$ Patricia C. Warouw \\ ${ }^{2}$ Erna Suparman \\ ${ }^{2}$ Freddy W. Wagey
}

\author{
${ }^{1}$ Kandidat Skripsi Fakultas Kedokteran Universitas Sam Ratulangi Manado \\ ${ }^{2}$ Bagian Obstetri dan Ginekologi Fakultas Kedokteran Universitas Sam Ratulangi Manado \\ Email: patriciaceciliawarouw@gmail.com
}

\begin{abstract}
Worldwide there are about 76,000 pregnant women die each year due to preeclampsia and other hypertensive disorders in pregnancy. The incidence rate of preeclampsia in the United States, Canada, and Western Europe ranges from 2-5\%. In developing countries, the rate ranges from $4-18 \%$ of all pregnancies. In Indonesia, the Maternal Mortality Ratio (MMR) of the period of 2008 to 2012 was 359 deaths per 100,000 live births. The occurrence of preeclampsia in Indonesia is about $3-10 \%$ of all pregnancies. This study aimed to determine the characteristics of patients with preeclampsia. This was a retrospective descriptive study. Samples were pregnant women with preeclampsia and had complete medical records at Prof. Dr. R. D. Kandou Hospital during the period of January 1, 2014 until December 31, 2014. The results showed that the number of pregnant women with preeclampsia were 201 people. Mild preeclampsia and severe preeclampsia were most prevalent in the age group of $20-35$ years $(70 \%$ and $61.46 \%)$ meanwhile superimposed preeclampsia in the age group of $>35$ years $(78.13 \%)$. Preeclampsia was mostly among multiparity. Superimposed preeclampsia was found in 32 cases. Most pregnant women with preeclampsia had a BMI $\geq 30.00$. Conclusion: Most preeclampsia cases occured in the age group of 20-35 and $>35$ years with multiparity, some had hypertension, and mostly were obese.
\end{abstract}

Keywords: mild preeclampsia, severe preeclampsia, superimposed preeclampsia, age, parity, nutritional status (obesity).

\begin{abstract}
Abstrak: Diseluruh dunia sekitar 76.000 wanita hamil meninggal setiap tahun akibat preeklamsia dan gangguan hipertensi lainnya pada kehamilan. Insiden preeklamsia di Amerika Serikat, Kanada, dan Eropa Barat berkisar 2-5\% sedangkan di negara berkembang berkisar 418\% dari semua kehamilan. Di Indonesia Maternal Mortality Ratio (MMR) periode 2008 sampai 2012 sebesar 359 kematian per 100.000 kelahiran hidup. Frekuensi kejadian preeklamsia di Indonesia sekitar 3-10\% dari semua jumlah kehamilan. Penelitian ini bertujuan untuk mengetahui karakteristik penderita preeklamsia. Jenis penelitian ini deskriptif retrospektif. Sampel penelitian ialah ibu hamil dengan preeklamsia dan mempunyai data rekam medis lengkap di RSUP Prof. Dr. R.D. Kandou periode 1 Januari 2014 sampai 31 Desember 2014. Hasil penelitian menunjukkan bahwa jumlah ibu hamil dengan preeklamsia 201 orang. PER dan PEB terbanyak ditemukan pada kelompok usia 20-35 tahun (70\% dan 61,46\%) sedangkan superimposed PE pada kelompok usia $>35$ tahun (78,13\%). Preeklamsi terbanyak pada paritas multigravida. Superimposed PE berjumlah 32 kasus. Ibu hamil dengan preeklamsia terbanyak memiliki IMT $\geq 30.00$. Simpulan: Preeklamsia terjadi pada kelompok usia 20-35 dan $>35$ tahun dengan paritas multipara, sebagian dengan riwayat hipertensi, dan sebagian besar disertai obesitas.
\end{abstract}

Kata kunci: preeklamsia ringan, preeklamsia berat, superimposed preeklamsia, usia, paritas, status gizi (obesitas). 
Secara global, $80 \%$ kematian ibu hamil yang tergolong dalam penyebab kematian ibu secara langsung disebabkan karena perdarahan (25\%) biasanya perdarahan pasca persalinan, hipertensi (12\%), partus macet (8\%), aborsi (13\%), dan sebab lainnya (7\%). ${ }^{1}$

Sepuluh juta wanita mengalami preeklamsia setiap tahun di seluruh dunia. Di seluruh dunia sekitar 76.000 wanita hamil yang meninggal setiap tahun oleh karena preeklamsia dan gangguan hipertensi pada kehamilan lainnya, dan jumlah bayi yang meninggal karena gangguan ini sekitar 500.000 per tahun. ${ }^{2}$ Preeklamsia dan hubungannya dengan gangguan hipertensi dalam kehamilan memengaruhi 5-8\% dari seluruh kelahiran di Amerika Serikat. Tingkat insiden untuk preeklamsia di Amerika Serikat, Kanada, dan Eropa Barat berkisar 2-5\%. Di negara berkembang, prevalensi preeklamsia dan eklamsia berkisar mulai dari 4\% dari semua kehamilan sampai $18 \%$ di beberapa bagian Afrika. Di Amerika Latin, preeklamsia merupakan penyebab pertama dari kematian maternal. $^{3}$

Tiga penyebab klasik kematian ibu yang paling dikenal di Indonesia di samping infeksi dan perdarahan ialah preeklamsia. ${ }^{4} \quad$ Berdasarkan Survei Demografi dan Kesehatan Indonesia (SDKI) tahun angka kematian ibu (AKI) atau Maternal Mortality Ratio (MMR) di Indonesia untuk periode 2008 sampai dengan 2012 ialah 359 kematian per 100.000 kelahiran hidup. Angka ini lebih tinggi dari hasil SDKI 2007 yang besarnya 228 per 100.000 kelahiran hidup. Kejadian preeklamsia dikatakan sebagai masalah kesehatan masyarakat bila Case Fatality Rate (CFR) preeklamsia mencapai 1,4\% sampai 1,8\%. Di Indonesia frekuensi kejadian preeklamsia sekitar 3-10\%. ${ }^{5}$

Data Dinas Kesehatan Provinsi Sulawesi Utara, angka kematian ibu untuk tahun 2013 sebanyak 77 kematian dengan kasus preeklamsia dan eklamsia 18 kasus. Dilihat dari data yang ada, preeklamsia/ eklamsia menjadi penyebab ketiga terbanyak dari kasus kematian ibu di
Provinsi Sulawesi Utara setelah perdarahan dan kasus lainnya. ${ }^{6}$

Di RSUP Prof. Dr. R. D. Kandou Manado tahun 2011 angka kejadian preeklamsia ringan 314 kasus (7,6\%), preeklamsia berat 103 kasus (2,5\%) dari 4.147 persalinan. Tahun 2012 angka kejadian preeklamsia ringan sebanyak 378 kasus (7,1\%) preeklamsia berat 227 kasus (4,5\%) dari 5.320 persallinan sedangkan tahun 2013 angka kejadian preeklamsia ringan 452 kasus (8,5\%) preeklamsia berat 205 kasus (3,8\%) dari 5.258 persalinan. Berdasaarkan data di atas dapat disimpulkan kejadian preeklamsia di RSUP Prof. Dr. R. D. Kandou Manado masih cukup tinggi. ${ }^{6}$ Penelitian ini bertujuan untuk mendapatkan karakteristik penderita preeklamsia di RSUP Prof. Dr. R. D. Kandou Manado.

\section{METODE PENELITIAN}

Jenis penelitian ini ialah deskriptif retrospektif. Penelitian ini dilakukan di RSUP Prof. Dr. R. D. Kandou Manado pada bulan November 2015 sampai Desember 2015 dengan menggunakan catatan rekam medis pasien.

Sampel penelitian ini ialah ibu hamil dengan preeklamsia yang memiliki data rekam medis lengkap di RSUP Prof. Dr. R. D. Kandou Manado periode 1 Januari 2014 sampai 31 Desember 2014. Kriteria eksklusi penelitian ini ialah gemeli. Data yang diperoleh diolah menggunakan Microsoft Excel dan disajikan dalam bentuk tabel.

\section{HASIL PENELITIAN}

Pada periode 1 Januari 2014 sampai 31 Desember 2014 tercatat jumlah kasus yang terdiagnosis preeklamsia sebanyak 201 kasus dari 3347 persalinan.

Pada Tabel 1 terlihat bahwa ibu hamil dengan preeklamsia ringan (PER) dan preeklamsia berat (PEB) paling banyak pada kelompok usia 20-35 tahun dan superimposed PE pada kelompok usia $>35$ tahun.

Pada Tabel 2 terlihat bahwa ibu hamil dengan PER, PEB, dan superimposed PE 
paling banyak ditemukan pada preeklamsia sebanyak 32 orang. multigravida.

Pada Tabel 4 terlihat bahwa ibu hamil

Pada Tabel 3 terlihat bahwa ibu hamil dengan preeklamsia yang memiliki riwayat hipertensi sebelumnya atau superimposed dengan preeklamsia sebagian besar disertai dengan obesitas (IMT $\geq 30,00)$.

Tabel 1. Distribusi penderita preeklamsia berdasarkan usia

\begin{tabular}{lcccccc}
\hline \multirow{2}{*}{ Usia Ibu } & \multicolumn{2}{c}{ PER } & \multicolumn{2}{c}{ PEB } & \multicolumn{2}{c}{ Superimposed PE } \\
\cline { 2 - 7 } \multicolumn{1}{c}{$\mathrm{n}$} & $\%$ & $\mathrm{~N}$ & $\%$ & $\mathrm{~N}$ & $\%$ \\
\hline$<$ 20 Tahun & 3 & 5 & 15 & 13,77 & - & - \\
20-35 Tahun & 42 & 70 & 67 & 61,46 & 7 & 21,87 \\
$>$ 35 Tahun & 15 & 25 & 27 & 24,77 & 25 & 78,13 \\
Total & $\mathbf{6 0}$ & $\mathbf{1 0 0}$ & $\mathbf{1 0 9}$ & $\mathbf{1 0 0}$ & $\mathbf{3 2}$ & $\mathbf{1 0 0}$ \\
\hline
\end{tabular}

Tabel 2. Distribusi penderita preeklamsia berdasarkan paritas

\begin{tabular}{lcccccc}
\hline \multirow{2}{*}{ Paritas } & \multicolumn{2}{c}{ PER } & \multicolumn{2}{c}{ PEB } & \multicolumn{2}{c}{ Superimposed PE } \\
\cline { 2 - 7 } & $\mathrm{n}$ & $\%$ & $\mathrm{~N}$ & $\%$ & $\mathrm{~N}$ & $\%$ \\
\hline Primigravida & 18 & 30 & 54 & 49,54 & - & - \\
Multigravida & 42 & 70 & 55 & 50,46 & 32 & 100 \\
Total & $\mathbf{6 0}$ & $\mathbf{1 0 0}$ & $\mathbf{1 0 9}$ & $\mathbf{1 0 0}$ & $\mathbf{3 2}$ & $\mathbf{1 0 0}$ \\
\hline
\end{tabular}

Tabel 3. Distribusi penderita preeklamsia berdasarkan riwayat hipertensi sebelumnya (superimposed preeklamsi)

\begin{tabular}{lcccccc}
\hline \multicolumn{1}{c}{ Riwayat } & \multicolumn{2}{c}{ PER } & \multicolumn{2}{c}{ PEB } & \multicolumn{2}{c}{ Superimposed PE } \\
\cline { 2 - 7 } \multicolumn{1}{c}{ Hipertensi } & $\mathrm{n}$ & $\%$ & $\mathrm{n}$ & $\%$ & $\mathrm{~N}$ & $\%$ \\
\hline Ada riwayat & - & - & - & & 32 & 100 \\
Tanpa riwayat & 60 & 100 & 109 & 100 & - & - \\
Total & $\mathbf{6 0}$ & $\mathbf{1 0 0}$ & $\mathbf{1 0 9}$ & $\mathbf{1 0 0}$ & $\mathbf{3 2}$ & $\mathbf{1 0 0}$ \\
\hline
\end{tabular}

Tabel 4. Distribusi penderita preeklamsia berdasarkan status gizi (IMT)

\begin{tabular}{|c|c|c|c|c|c|c|}
\hline \multirow{2}{*}{$\begin{array}{l}\text { Status Gizi } \\
\text { (IMT) }\end{array}$} & \multicolumn{2}{|c|}{ PER } & \multicolumn{2}{|c|}{ PEB } & \multicolumn{2}{|c|}{ Superimposed PE } \\
\hline & $\mathrm{n}$ & $\%$ & $\mathrm{n}$ & $\%$ & $\mathrm{~N}$ & $\%$ \\
\hline $\begin{array}{l}\text { Underweight } \\
<18,50\end{array}$ & - & - & 1 & 0,92 & - & - \\
\hline $\begin{array}{l}\text { Normal } \\
18,50 \text { - 24,99 }\end{array}$ & 13 & 21,66 & 13 & 11,92 & 2 & 6,25 \\
\hline $\begin{array}{l}\text { Overweight } \\
\geq 25.00\end{array}$ & 19 & 31,67 & 33 & 30,28 & 12 & 37,5 \\
\hline $\begin{array}{l}\text { Obesitas } \\
\geq 30.00\end{array}$ & 28 & 46.67 & 62 & 56,88 & 18 & 56,25 \\
\hline$\overline{\text { Total }}$ & 60 & 100 & 109 & 100 & 32 & 100 \\
\hline
\end{tabular}

\section{BAHASAN}

Preeklamsia adalah hipertensi yang timbul setelah 20 minggu kehamilan disertai dengan proteinuria. ${ }^{4}$ Dari gejalagejala klinik preeklamsia dapat dibagi menjadi preeklamsia ringan dan preeklamsia berat. Pembagian preeklamsia menjadi ringan dan berat tidak berarti terdapat dua penyakit yang jelas berbeda. Dahulu disebut preeklamsia jika dijumpai trias tanda klinik yaitu: tekanan darah $\geq 140 / 90 \mathrm{mmHg}$, proteinuria, dan edema. Sekarang edema tidak lagi dimasukkan dalam kriteria diagnostik karena edema 
juga dijumpai pada kehamilan normal.,

Pada penelitian ini didapatkan bahwa dari 3.347 ibu hamil yang menjalani persalinan terdapat 201 ibu hamil yang menderita preeklamsia di RSUP Prof. Dr. R. D. Kandou Manado periode 1 Januari 2014 sampai 31 Desember 2014. Data tersebut terdiri dari 60 penderita preeklamsia ringan, 109 penderita preeklamsia berat, dan 32 penderita superimposed preeklamsia. Bila dibandingkan dengan kasus preeklamsia periode tahun 2011 sampai tahun 2013, angka kejadian preeklamsia pada tahun 2014 mengalami penurunan namun masih termasuk banyak.

Pada Tabel 1, preeklamsia ringan dan preeklamsia berat paling banyak ditemukan pada kelompok umur 20-35 tahun, yaitu preeklamsia ringan 42 kasus (70\%), preeklamsia berat 67 kasus (61,46\%) sedangkan superimposed preeklamsia paling banyak ditemukan pada kelompok umur $>35$ tahun, yaitu 25 kasus (78,13\%). Teori menyatakan bahwa usia yang berisiko terjadi gangguan dalam kehamilan adalah usia $<20$ tahun atau $>35$ tahun dan faktor risiko terjadinya preeklamsia umumnya terjadi pada usia $>35$ tahun. ${ }^{14,15}$ Hasil penelitian yang dilakukan oleh Langelo et al. $^{8}$ dan Gafur et al. ${ }^{9}$ tahun 2011-2012 menunjukan terdapat hubungan yang signifikan antara usia ibu dengan preeklamsia. Hal ini menunjukkan bahwa tidak semua kelompok usia 20-35 tahun kemungkinan besar tidak akan mengalami kejadian preeklamsia di RSUP. Prof. dr. R. D. Kandou Manado tahun 2014

Pada Tabel 2, preeklamsia paling banyak ditemukan pada paritas multigravida, yaitu preeklamsia ringan 42 kasus (70\%), preeklamsia berat 55 kasus (50,46\%), dan superimposed preeklamsia 32 kasus. Hasil penelitian ini tidak sejalan dengan teori yang menyatakan bahwa preeklamsia sering terjadi pada kehamilan pertama (primigravida). ${ }^{10}$ Penelitian yang serupa oleh Dini et al. ${ }^{11}$ menunjukkan bahwa tidak terdapat hubungan bermakna antara paritas dengan kejadian preeklamsia di RSUD dr. Adjidarmo Rangkasbitung periode Juli sampai Desember tahun 2011.

Pada Tabel 3 di temukan bahwa ibu hamil dengan preeklamsia yang memiliki riwayat hipertensi sebelumnya atau dapat didiagnosis superimposed preeklamsia periode 1 Januari - 31 Desember 2014 sebanyak 32 kasus. Berdasarkan penelitian yang dilakukan oleh Vonny et al. ${ }^{12}$ tahun didapatkan terdapat hubungan riwayat hipertensi dengan kejadian preeklamsia. Ibu hamil dengan riwayat hipertensi akan mempunyai risiko lebih besar untuk mengalami superimposed preeklamsia. ${ }^{12}$

Pada Tabel 4 ditemukan bahwa ibu hamil dengan preeklamsia paling banyak disertai dengan obesitas (IMT $\geq 30.00$ ), yaitu preeklamsia ringan 28 kasus (46,67\%), preeklamsia berat 62 kasus (56,88\%), dan superimposed preeklamsia 18 kasus (56,25\%). Penelitian sebelumnya oleh Hermanto et al. ${ }^{13}$ menunjukkan terdapat hubungan bermakna antara peningkatan berat badan ibu saat kehamilan dengan preeklamsia $(\mathrm{P}=0,003)$. Pada wanita dengan peningkatan berat badan tinggi berisiko hampir tiga kali lebih besar untuk menderita preeklamsia dibandingkan wanita yang peningkatan berat badan saat hamilnya normal.

Dalam penelitian ini terdapat beberapa keterbatasan, antara lain:

1. Data pasien dalam rekam medik banyak yang tidak lengkap.

2. Status gizi ibu hamil diambil pada akhir kehamilan berupa data tinggi badan dan berat badan untuk pengukuran IMT yang seharusnya digunakan pengukuran IMT pada awal kehamilan.

\section{SIMPULAN}

Berdasarkan hasil penelitian dan bahasan dapat disimpulkan bahwa:

1. Usia terbanyak PER dan PEB ialah kelompok usia 20-35 tahun sedangkan superimposed $\mathrm{PE}>35$ tahun.

2. Paritas PER, PEB, dan superimposed PE paling banyak pada multigravida

3. Ibu hamil dengan riwayat hipertensi berisiko mengalami preeklamsia/ superimposed preeklamsia. Angka kejadian lebih sedikit dibandingkan 
dengan PER dan PEB.

4. Ibu hamil yang menderita preeklamsia sebagian besar memiliki IMT $>30,00$ (obesitas).

\section{DAFTAR PUSTAKA}

1. Preeclampsia and maternal mortality. A Global Burden. 2013. [cited 15 Oktober 2015]. Available from: http://.preeclampsia.org/healthinformation/149-advocacyawarenes/332-preeclampsia-andmaternal-mortality-a-global-burden

2. Maternal mortality in 2005: Estimates developed by WHO, UNICEF, UNIFPA and the World Bank, Geneva, World Health Organization, 2007. [cited 15 Oktober 2015] Available from: http: //www.who.int/maternal_child_adole scent/documents/9789241596213/en/

3. Preeclampsia: A Decade of perspective, building a global call to action. Preeclampsia Foundation, Melbourne, Florida. November 2010. [cited 17 Oktober 2015]. Available from: http: //www.preeclampsia.org/ component/content/article/149advocacy-awareness/332preeclampsia-and-maternalmortality-a-global-burden

4. Prawirohardjo S. Ilmu Kebidanan (4th ed). Jakarta: Yayasan Bina Pustaka, 2014; p. 531.

5. SDKI. 2012. Surfei Demografi Kesehatan Indonesia. [cited 15 Oktober 2015]. Available from: http: //www.bkkbn.go.id/ViewBerita.aspx? BeritaID $=900$

6. Puradin N. Faktor-faktor yang berhubungan dengan kejadian preeklamsi di ruang bersalin BLURSUP. Prof. Dr. R. D. Kandou Manado Tahun 2013. Manado; 2014

7. Fadlun, Feryanto A. Asuhan Kebidanan Patologis. Jakarta: Salemba Medika, 2014.

8. Langelo W, Arsin AA, Russeng S. Faktor risiko Preeklamsi di RSKD. Ibu dan Anak Siti Fatimah Makassar Tahun
2011-2012 [Tesis]. Makassar: Universitas Hasanuddin; 2012.

9. Gafur A, Nurdin A, Ramadhany S, Rahim R. (2012). Jurnal: Hubungan antara Primigravida dengan Preeklamsi. Jurnal online Fakultas Kedokteran Universitas Muhammadiyah Makassar. 2011. [cited tanggal 28 Desember 2015]. Available from: http://www.jurnal.med.unismuh.ac.id /hubungan-antara-promigravidadengan-preeklampsia/

10.Sudinaya IP. Insiden Preeklamsi - Eklamsi di RSU Tarakan Kalimantan Timur Tahun 2000. 2007. [cited 23 Desember 2015]. Available from: http:

//www.cerminduniakedokteran.co.id.

11.Dini DJ, Bambang K. Hubungan umur dan paritas ibu dengan kejadian preeklamsi. E-Jurnal Obstetrika. 2013. [cited 23 Desember 2015]. Available from: http: //ejurnal.latansamashiro.ac.id/index.p hp/Ejobs/article/view/141/135

12.Vonny KD. Hubungan Obesitas dan Riwayat Hipertensi dengan Kejadian Preeklamsi di Puskesmas Rawat Inap Danau Panggang. [cited 23 Desember 2015]. 2014. Available from: http://ojs.uniska-bjm.ac.id/ index.php/ANN/article/view/217/210

13.Hermanto Q, John W, Juneke J. Hubungan indeks massa tubuh dan peningkatan berat badan saat kehamilan dengan preeklamsi. 2013. [cited 22 Desember 2015]. Available from: http: //ejournal.unsrat.ac.id

14.Cut MI. Hubungan Usia Ibu Hamil Dengan Angka Kejadian Preeklamsi Di RSUD dr. Zainoel Abidin Banda Aceh. 2013. [cited 23 Desember 2015]. Available from: http://etd.unsyiah.ac.id/baca/index.ph p?id=2977\&page $=1$

15.Robson E. Patologi dalam kehamilan. Manajemen dan Asuhan Kebidanan. Jakarta: EGC, 2012. 